\title{
Pensiones y el punto ciego de las
}

"COMISIONES FANTASMAS"

Por Fernando López

Ph.D. en Finanzas, Washington University in St. Louis, Estados Unidos. Académico FEN UAH

\begin{abstract}
| Comisiones Fantasmas", "Comisiones Ocultas" y "Comisiones de Intermediación" son algunos de los términos usados para referirse a los pagos que las AFP realizan con recursos de los fondos de pensiones por las inversiones que estos realizan a través de fondos y entidades mandatarias nacionales y extranjeras.

Las comisiones pagadas a estos "gestores externos" han sido uno de los temas controversiales y mediáticos del debate previsional. Desafortunadamente, esta discusión se ha polarizado entre férreos defensores y detractores sin que todavía tengamos respuesta a la pregunta del millón: ¿Cuánto valor agrega el pago de estas comisiones a los fondos de pensiones? Este es el gran punto ciego del debate en torno a las comisiones fantasmas.
\end{abstract}

\section{Inversión realizada a través de ges- tores externos}

A nivel internacional, es común que inversionistas institucionales inviertan a través de fondos y entidades mandatarias. En el caso de nuestros fondos de pensiones, al cuarto trimestre de 2017, el monto invertido por esta vía ascendió a $44,1 \%$ de los activos bajo administración, equivalentes a 91 mil 831 millones de dólares ( $31 \%$ del PIB). A nivel de multifondos, el porcentaje de inversión delegada fue un $77,4 \%$ para el Fondo $A, 59,7 \%$ para el $B, 43,7 \%$ para el $\mathrm{C}, 27,7 \%$ para el $\mathrm{D}$ y $9 \%$ para el $\mathrm{E}$.

El Gráfico 1 muestra que el porcentaje de inversión delegada ha aumentado sostenidamente desde 2002. Esta evolución se explica principalmente porque el límite máximo de inversión internacional agregado para el conjunto de los fondos de pensiones aumentó de un $20 \%$ al $80 \%$, los fondos más riesgosos invierten una mayor fracción de sus activos en el extranjero y el grueso de la inversión internacional se realiza a través de gestores externos.

\section{Comisiones máximas}

Desde el 2002, las comisiones máximas que los fondos de pensiones pueden pagar a los gestores externos se han definido conjuntamente por las superintendencias de Pensiones,

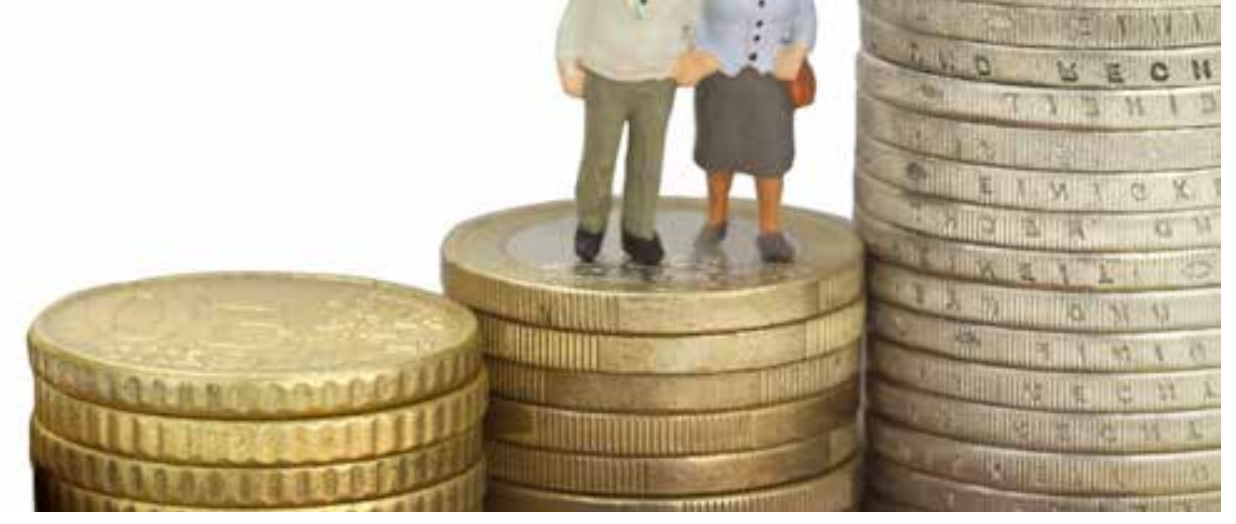

\section{$\%$ de los fondos de pensiones delegados a gestores externos}

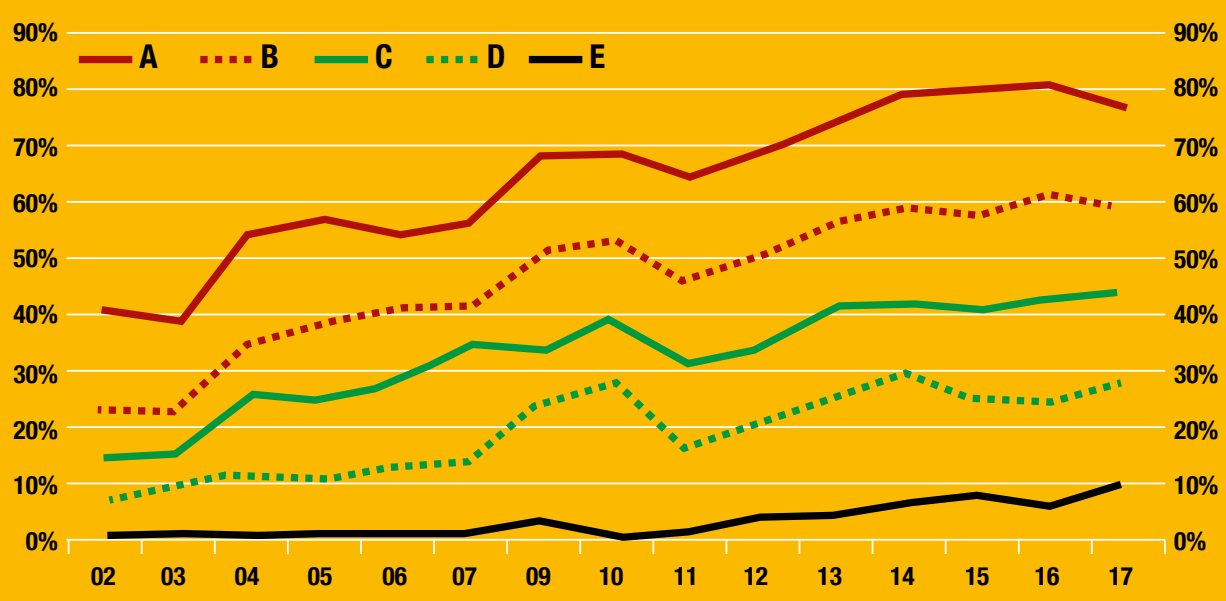

Fuente: Elaboración propia con datos de la Superintendencia de Pensiones.

de Bancos e Instituciones Financieras y de Valores y Seguros (actual Comisión del Mercado Financiero). El procedimiento con que se determina esta cifra considera como referencia los niveles de comisiones reportados en bases de

\section{"Todavía no tenemos} respuesta a la pregunta del millón: ¿Cuánto valor agrega el pago de estas comisiones a los fondos de pensiones?" datos nacionales e internacionales, así como las características de los vehículos de inversión (tipo de activos, zona geográfica y volumen de inversión). Si las comisiones son superiores a los máximos establecidos, estas deben ser pagadas por las AFPs.

Desde la creación de los multifondos, un $90,7 \%$ de las inversiones delegadas tuvieron como destino los mercados internacionales. La comisión pagada como porcentaje de la inversión internacional delegada cayó de un $0,93 \%$ al 0,61\% en el periodo 2002-12, para luego estabilizarse en torno a un promedio de $0,59 \%$ en el periodo 2013-17.

El Gráfico 2 muestra la evolución de estas comisiones a nivel de multifondos. Se aprecia que 


\section{Comisiones pagadas a gestores de fondos internacionales (\% de los fondos administrativos)}

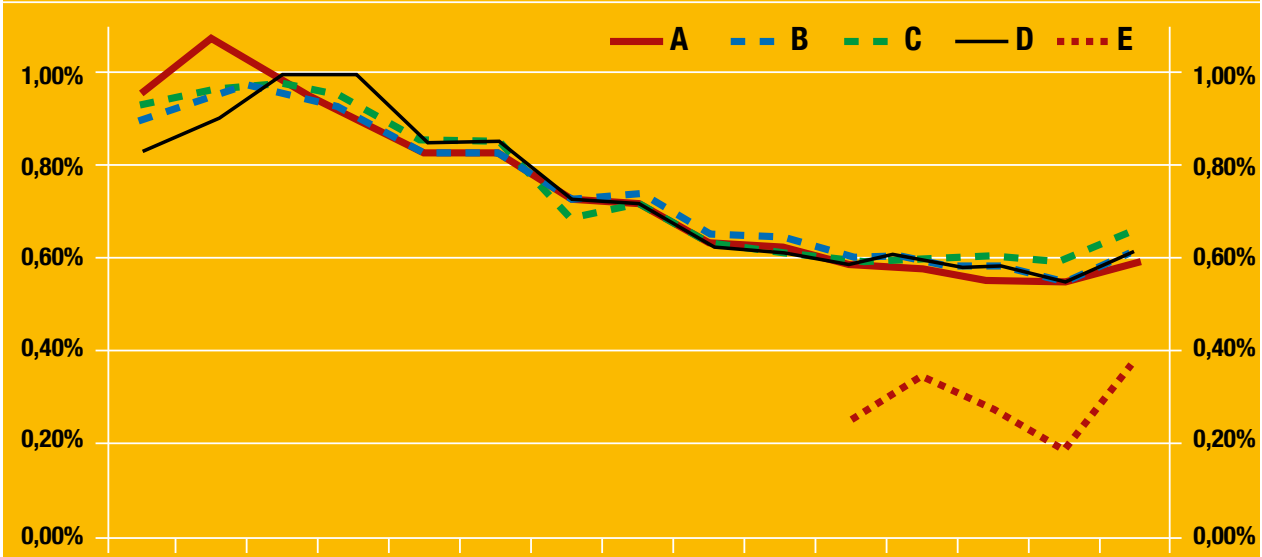

$\begin{array}{lllllllllllllll}02 & 03 & 04 & 05 & 06 & 07 & 09 & 10 & 11 & 12 & 13 & 14 & 15 & 16 & 17\end{array}$

Fuente: Elaboración propia con datos de la Superintendencia de Pensiones.

desde su creación, los fondos A-D han seguido un patrón similar al de la comisión agregada pagada a gestores de inversiones internacionales. En el caso del Fondo $E$, las comisiones en el periodo 2013-17 han sido inferiores a las pagadas por el resto de los fondos, fluctuando entre un $0,19 \%$ y $0,35 \%$.

\section{El debate}

Aunque el clímax mediático de las comisiones fantasmas ocurrió en 2016, estas ya habían sido discutidas en la Comisión Bravo. De hecho, una de las cuatro propuestas orientadas a aumentar la competencia en la industria de AFP proponía que estas fueran enteramente asumidas por las AFP y no por los afiliados. De los 24 miembros que participaron en esta instancia, 13 votaron a favor, 7 en contra y 4 se abstuvieron. Entre los argumentos a favor de la medida se planteaba que estas comisiones podrían ser consideradas como costos de administración de las AFP, lo cual aumentaría la transparencia de las comisiones pagadas por los afiliados, se reducirían las comisiones totales y aumentarían las pensiones. Los detractores planteaban que estos efectos podrían ser ambiguos si las AFPs decidieran minimizar estos costos invirtiendo en portafolios ineficientes o de manera sub-óptima en relación al interés del afiliado.

Más allá de su efectividad como instrumento

1. Considerando el tipo de cambio del último día hábil de diciembre de 2017.

2. El cálculo supone que un aumento permanente de $1 \%$ en la rentabilidad de los fondos aumenta en $25 \%$ las pensiones de quienes se incorporen al mercado laboral. para promover competencia en la industria de AFP, la regulación de estas comisiones es relevante porque afecta los incentivos de inversión de los fondos de pensiones. En efecto, las comisiones pagadas a gestores externos ascendieron a 513 millones de dólares durante 2017 , cifra que representa más del $90 \%$ de las utilidades después de impuestos obtenidas por la industria en el periodo'. Si una parte de estas comisiones fueran asumidas por las AFPs, estas optarían por vehículos de inversión de menor costo, alterando sus incentivos de inversión. Sin embargo, no es claro que esta medida aumente las pensiones o incentive la inversión en portafolios subóptimos, como planteaban los miembros de la Comisión Bravo que votaron a favor y en contra de la propuesta, respectivamente.

\section{El punto ciego}

En la implementación de la gestión delegada, las AFPs seleccionan vehículos de inversión ad-

\section{"Las comisiones pagadas} a gestores externos ascendieron a 513 millones de dólares durante 2017, cifra que representa más del $90 \%$ de las utilidades después de impuestos obtenidas por la industria en el periodo" ministrados por gestores "activos", que apuntan a identificar mercados y activos que tendrán un desempeño sobresaliente. Estos gestores cobran comisiones que superan a las que se pagarían a través de alternativas de bajo costo. En efecto, las comisiones que se pagarían por la inversión en fondos que intentan replicar las rentabilidades alcanzadas por índices representativos de mercados de renta fija y renta variable global difícilmente superarían el 0,10\% de los activos bajo administración (versus 0,59\% en el caso de nuestros fondos de pensiones en el periodo 2013-17).

Para que las comisiones pagadas por los fondos de pensiones a gestores externos agreguen valor, su rentabilidad promedio debería superar por más de un $0,50 \%$ la rentabilidad alcanzada por vehículos de inversión de bajo costo representativos de mercados con riesgo similar. La medida en que esto ocurra dependerá de la capacidad que tengan los gestores activos para identificar los mercados y activos que efectivamente logren un desempeño sobresaliente. Del mismo modo, cuando los fondos de bajo costo implementan las transacciones necesarias para ajustar sus portafolios a los cambios que experimentan los índices que tratan de replicar (asociados a emisiones de acciones, pago de dividendos, recompras de acciones o cambios en los activos que pertenecen a dichos índices), estos podrían tener una menor capacidad para identificar el momento oportuno y mejores condiciones de precio respecto a los gestores activos.

Para ilustrar la relevancia de cuantificar el valor agregado de las comisiones pagadas a gestores externos, consideremos el Fondo A, que delega un $77,4 \%$ de su cartera. Una diferencia permanente de $0,30 \%$ en la rentabilidad neta de comisiones tendrá un impacto de 5,8\% en las pensiones de los afiliados en el largo plazo $^{2}$. Este impacto es superior al que se observaría con un aumento de $1 \%$ en la cotización obligatoria de quienes se mantengan en el Fondo A.

La ausencia de estudios de desempeño se explica principalmente por la falta de interés del mundo académico y de las entidades regulatorias. La buena noticia es que existen profesionales con las competencias necesarias para realizarlos, tanto en Chile como el extranjero, y su costo es una fracción marginal de los 91 mil millones de dólares delegados a gestores externos.

Esperemos que en un futuro no muy lejano contemos con los elementos de juicio para iluminar este punto ciego de las comisiones fantasmas. $\mathbf{E}$ 